IRA-International Journal of Technology \& Engineering ISSN 2455-4480

Proceedings of the

International Conference on Science \&

Engineering for Sustainable Development (2017)

Pg. no.286-294

Published by: Institute of Research Advances

https://research-advances.org/index.php/IRAJTE

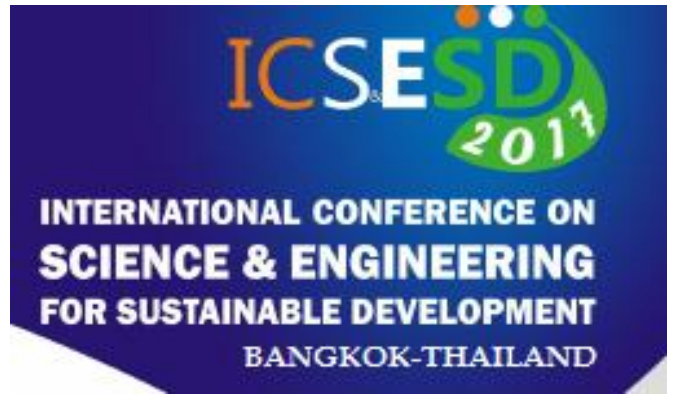

\title{
Design and Development of Vertical Axis Wind Turbine
}

\author{
Samir J. Deshmukh*1, Sagar M.Charthal ${ }^{2}$ \\ ${ }^{1}$ Associate Professor, Department of Mechanical Engineering, Prof. Ram Meghe Institute \\ of Technology \&Research Badnera-Amravati, SGB Amravati University, India. \\ (Email-aryasamir@ rediffmail.com) \\ ${ }^{2}$ Research Scholar, Prof. Ram Meghe Institute of Technology \& Research Badnera- \\ Amravati, SGB Amravati University, India. \\ (Email-srcharthal121@gmail.com)
}

Type of Review: Originality Check \& Peer Review under the responsibility of the Scientific Committee of the Conference and The Institution of Engineers (India). DOI: http://dx.doi.org/10.21013/jte.ICSESD201728

\section{How to cite this paper:}

Deshmukh, S., Charthal, S. (2017). Design and Development of Vertical Axis Wind Turbine. Proceedings of the International Conference on Science \& Engineering for Sustainable Development (2017), 286-294. doi: http://dx.doi.org/10.21013/ite.ICSESD201728

(C) International Conference on Science \& Engineering for Sustainable Development\& The Institution of Engineers (India).

\section{(cc) BY-Ne}

This work is licensed under a Creative Commons Attribution-Non Commercial 4.0 International License subject to proper citation to the publication source of the work.

Disclaimer: The conference papers as published by the Institute of Research Advances (IRA) are the views and opinions of their respective authors and are not the views or opinions of the IRA. The IRA disclaims of any harm or loss caused due to the published content to any party. 


\section{ABSTRACT}

Wind energy is the kinetic energy associated with movement of large masses of air. These motions result from uneven heating of atmosphere by sun creating temperature, density, pressure differences. It is an indirect form of solar energy The device used to convert kinetic energy of wind into electrical power is called a wind turbine. Vertical Axis wind power generators, represent a very promising future for wind power generation.

In present study an attempt is made to utilize at low velocity wind below $4 \mathrm{~m} / \mathrm{s}$ for useful power generation using magnetic levitation for vertical axis wind turbine (VAWT) termed as Maglev turbine. A single large Maglev turbine can give output more than conventional horizontal axis wind turbine (HAWT). The rotor that is designed to harness enough air to rotate the shaft at low and high wind speeds while keeping the centre of mass closer to the base of yielding stability due to Maglev effect. The efficiency of turbine is increased by replacing the conventional bearings by magnets in repulsion; the magnetic levitation helps the turbine to spin at much faster rate as it eliminates the stresses on the shaft of turbine. The major components are placed at the ground level which ensures the safety of turbine.

Keyword: VAWT, HAWT, Maglev Turbine

\section{INTRODUCTION}

VAWTs are a type of wind turbine which were first designed by Croatian inventor, Fausto Veranzio, in 1595. The main rotor shaft is set transverse to the wind while the main components are located at the base of the turbine. This arrangement allows the generator and gearbox to be located close to the ground, facilitating service and repair. VAWTs do not need to be pointed into the wind, which removes the need for wind-sensing and orientation mechanisms.

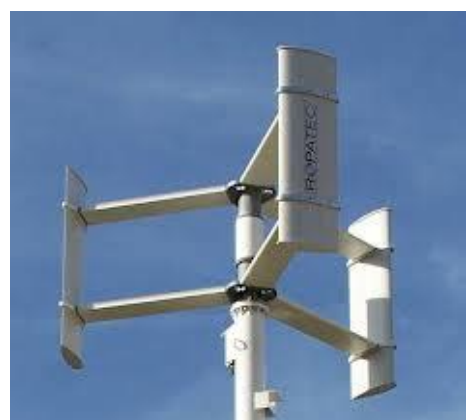

Fig.1 Vertical axis Wind Turbine

Horizontal Axis Wind Turbine (HAWT):-

HAWT have the main rotor shaft and electrical generator at the top of a tower, and must be pointed into the wind. Small turbines are pointed by a simple wind vane, while large turbines generally use a wind sensor coupled with a servo motor. Most have a gearbox, which turns the slow rotation of the blades into a quicker rotation that is more suitable to drive an electrical generator.

Table No.1 Comparison between HAWT and VAWT

\begin{tabular}{|c|l|c|c|}
\hline Number & Performance & Horizontal axis & Vertical axis \\
\hline 1 & Power generation efficiency & $50 \%-60 \%$ & Above $70 \%$ \\
\hline 2 & Electromagnetic interference & Yes & No \\
\hline
\end{tabular}




\begin{tabular}{|c|l|c|c|}
\hline 3 & Steering mechanism of wind & Yes & No \\
\hline 4 & Gear box & Above 10kw;yes & No \\
\hline 5 & Blade rotation space & Quite large & Quite small \\
\hline 6 & Wind-resistance capability & Weak & Strong \\
\hline 7 & Noise & $5-60 \mathrm{db}$ & $0-10 \mathrm{db}$ \\
\hline 8 & Starting wind speed & High $(2.5-5 \mathrm{~m} / \mathrm{s})$ & Low $(1.5-3 \mathrm{~m} / \mathrm{s})$ \\
\hline 11 & Maintenance & complicated & convenient \\
\hline 12 & Rotating speed & High & Low \\
\hline 13 & Effect of birds & Great & Small \\
\hline 15 & Power curve & & Full \\
\hline
\end{tabular}

Now in order to choose the design of wind turbine After analysing the above comparison and based on various other parameters such as Air velocity in Vidarbha region, it needs some design calculation of aerofoil shape blade for obtaining maximum power output in minimum air velocity

\section{Design of vertical axis wind turbine}

The main components of the vertical wind turbine are:-

A Aerofoil Blades

B. Radial arms

C. Shaft

\subsection{Aerofoil Blades:}

The standard forms of all aerofoils were proposed by National Advisory Committee for Aeronautics (NACA) which is now known as NASA. It is given as NACA ' $\mathrm{x} 1 \times 2 \times 3 \times 4$ '. Where 'first digit $\mathrm{x} 1$ ' describes maximum camber as percentage of the chord length, the 'second digit $\mathrm{x} 2$ ' describes the distance of maximum camber from the aerofoil leading edge in tens of percents of the chord and 'the last two $\times 3 \times 4$ ' describe maximum thickness of the aerofoil as percent of the chord.

For the present study it was decided to go with a symmetrical type of aerofoil i.e. NACA 0015 due to its simplicity mainly in fabrication. It has maximum thickness equal to fifteen percent of chord length, and ' 00 ' indicates that there is no camber present in the aerofoil shape.

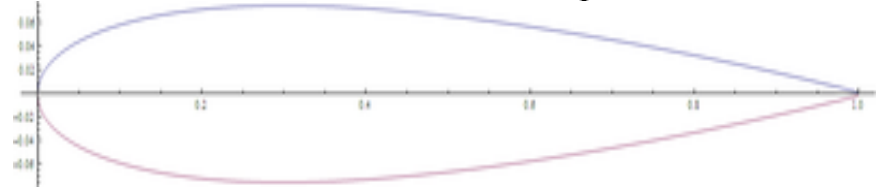

Fig 2 NACA 0015 Aerofoil

The equation to calculate half thickness (height of aerofoil above or below axis of symmetry is as follows

$$
y=\frac{t}{0.2} c\left[0.2969 \sqrt{\frac{x}{c}}-0.1260\left(\frac{x}{c}\right)-0.3516\left(\frac{x}{c}\right)^{2}+0.2843\left(\frac{x}{c}\right)^{3}-0.1015\left(\frac{x}{c}\right)^{4}\right]
$$

Where, 
- $\mathrm{c}$ is the chord length,

- $\mathrm{x}$ is the position along the chord from 0 to $\mathrm{c}$,

- $y$ is the half thickness at a given value of $x$ (centerline to surface), and

- $\mathrm{t}$ is the maximum thickness as a fraction of the chord (so $100 \mathrm{t}$ gives the last two digits in the NACA 4-digit denomination

To initiate with the design, we assumed chord length 'cas $12 \mathrm{~cm}$ '.

Therefore,

Maximum thickness $=12 \times 0.15$

Maximum thickness $=1.8 \mathrm{~cm}$

Here the position along the chord (x) varies from 0 to 12 .

The positions for the calculation iterations along the chord length are as follows, $0.000,0.150,0.300,0.600,0.900,1.200,1.800,2.400,3.000,3.600,4.800,6.000,7.200,8.400$, $9.600,10.800,11.400,12.000$

On putting the values of ' $\mathrm{X}$ ' in above equation we will get the coordinates for aerofoil structure

At $\mathrm{X} 1=0.000 \mathrm{~cm}$

$$
\begin{aligned}
& Y_{1}=\frac{t}{0.2} c\left[0.2969 \sqrt{\frac{x_{1}}{c}}-0.1260\left(\frac{\mathrm{x}_{1}}{\mathrm{c}}\right)-0.3516\left(\frac{\mathrm{x}_{1}}{\mathrm{c}}\right)^{2}+0.2843\left(\frac{\mathrm{x}_{1}}{\mathrm{c}}\right)^{3}\right. \\
& \left.\quad-0.1015\left(\frac{\mathrm{x}_{1}}{\mathrm{c}}\right)^{4}\right] \\
& Y_{1}=\frac{\mathrm{t}}{0.2} \mathrm{c}\left[0.2969 \sqrt{\left.\frac{0}{\mathrm{c}}-0.1260\left(\frac{0}{\mathrm{c}}\right)-0.3516\left(\frac{0}{\mathrm{c}}\right)^{2}+0.2843\left(\frac{0}{\mathrm{c}}\right)^{3}-0.1015\left(\frac{0}{\mathrm{c}}\right)^{4}\right]}\right. \\
& \mathrm{Y} 1=0.00
\end{aligned}
$$

Similarly, whenX2 $=0.15$

$$
\begin{aligned}
Y_{2}=\frac{t}{0.2} c\left[0.2969 \sqrt{\frac{X_{2}}{c}}-0.1260\left(\frac{\mathrm{X}_{2}}{c}\right)-0.3516\left(\frac{\mathrm{x}_{2}}{\mathrm{c}}\right)^{2}+0.2843\left(\frac{\mathrm{x}_{2}}{\mathrm{c}}\right)^{3}-0.1015\left(\frac{\mathrm{X}_{2}}{\mathrm{c}}\right)^{4}\right] \\
\mathrm{Y}_{2}=\frac{0.15 \times 12}{0.2}\left[0.2969 \sqrt{\frac{0.15}{12}}-0.1260\left(\frac{0.15}{12}\right)-0.3516\left(\frac{0.15}{12}\right)^{2}+0.2843\left(\frac{0.15}{12}\right)^{3}\right. \\
\left.\quad-0.1015\left(\frac{0.15}{12}\right)^{4}\right] \\
\mathrm{Y} 2=0.28404 \mathrm{~cm}
\end{aligned}
$$

The calculations are done for all the $12 \mathrm{x}$ values and the results are shown in table below:-

Table 2 Coordinates of Twelve points on Aerofoil

\begin{tabular}{|c|c|c|}
\hline $\mathrm{X}$ & Y (Lower) & Y (Upper) \\
\hline 12 & 0.01896 & 0.01896 \\
\hline 11.40 & 0.12096 & 0.12096 \\
\hline 10.8 & 0.2232 & 0.2232 \\
\hline
\end{tabular}




\begin{tabular}{|c|c|c|}
\hline 7.2 & 0.68448 & 0.68448 \\
\hline 4.8 & 0.87048 & 0.87048 \\
\hline 3 & 0.89124 & 0.89124 \\
\hline 2.4 & 0.86064 & 0.86064 \\
\hline 1.8 & 0.80184 & 0.80184 \\
\hline 1.2 & 0.69996 & 0.69996 \\
\hline 0.9 & 0.6302 & 0.6302 \\
\hline 0.3 & 0.39456 & 0.39456 \\
\hline 0.00 & 0 & 0 \\
\hline
\end{tabular}

\subsection{Radial Arms :}

Plywood was chosen as a material for this component as the strength required here is relatively high. So two pieces of $9 \mathrm{~mm}$ thickness having dimensions as $50 \mathrm{~cm}$ x $40 \mathrm{~cm}$ were chosen as a raw material. Then by using a reference radial arm diagram drawn on a blank sheet, the arms were cut into the required shape from the pieces by using Zig-Zag machine.

\subsection{Shaft:}

Shaft is a rotating machine element which is used totransmit power from one source to another. The power is delivered to the shaft by some tangential force and the resultant torque set up within the shaft permits the power to be transferred to various machines linked up to the shaft. In this project, an aluminum shaftis used. Shaft is designed on the basis of "Maximum Shear Stress Theory" The shaft is usually circular, but may be square or cross section. They are solid but sometimes hollow shaft are also used. But we had used solid circular shaft.

2.4 Design Calculations for shaft:

Torque is the most important fact while dealing with shaft where

Torque, $\mathrm{T}=\mathrm{w} \times \mathrm{r}$

$\mathrm{W}=$ Sum of weights of the three Aerofoil blades;

$=\mathrm{W} 1+\mathrm{W} 2+\mathrm{W} 3=3 \mathrm{~W}$

$=3 \times 0.5$

$=1.5 \mathrm{~kg}$

$\mathrm{W}=1.5 \times 9.81=14.715 \mathrm{~N}$

Radius of radial arm is found to be $18.5 \mathrm{~cm}$

$\mathrm{T}=\mathrm{W} \times \mathrm{r}=14.715 \times 185$

$$
=2722.275 \mathrm{Nmm}=2.72 \mathrm{Nm}
$$

Torsion Equation is given by

$$
\begin{aligned}
\frac{\mathrm{T}}{\mathrm{J}}=\frac{\tau}{\mathrm{r}} \\
\mathrm{T}=\frac{\pi}{16} \tau \mathrm{d}^{3} \\
\tau=\frac{2.72 \times 16}{\pi \times 0.012^{3}} \\
\tau=8.0016 \times 106 \mathrm{~N} / \mathrm{m} 2
\end{aligned}
$$

Dimension of Shaft :

Based on the calculations the shaft diameter is determined as $12 \mathrm{~mm}$. To reduce the weight of the shaft, the material was selected as aluminum due to its low weight and sufficient strength. 
Table 3 Dimensions of the shaft

\begin{tabular}{|c|l|c|}
\hline Sr.No & Description & Dimension(cm) \\
\hline 1 & Diameter of shaft & 1.2 \\
\hline 2 & Length of shaft & 100 \\
\hline
\end{tabular}

The following tables show the observations at various wind velocities and different rigging angles: At air velocity of $7 \mathrm{~m} / \mathrm{s}$

\begin{tabular}{|c|c|c|c|c|}
\hline Angle & RPM & Voltage & $\begin{array}{l}\text { Current } \\
(\mathrm{mA})\end{array}$ & power $(\mathrm{P}=\mathrm{V} \times \mathrm{I})$ \\
\hline 0 & 107 & 4.56 & 5.2 & 23.71 \\
\hline 30 & 114 & 4.21 & 5.0 & 21.05 \\
\hline 60 & 80 & 3.3 & 3.4 & 11.22 \\
\hline 90 & 190 & 8.3 & 19.2 & 159.36 \\
\hline
\end{tabular}

At air velocity of $2 \mathrm{~m} / \mathrm{s}$

\begin{tabular}{|c|c|c|c|c|}
\hline Angle & RPM & Voltage & Current(mA) & Power(P=V×I) \\
\hline 0 & 39 & 1.8 & 2.0 & 3.6 \\
\hline 30 & 30 & 1.3 & 0.9 & 1.17 \\
\hline 60 & 20 & 0.7 & 0.6 & 0.44 \\
\hline 90 & 120 & 4.0 & 12.5 & 50 \\
\hline
\end{tabular}

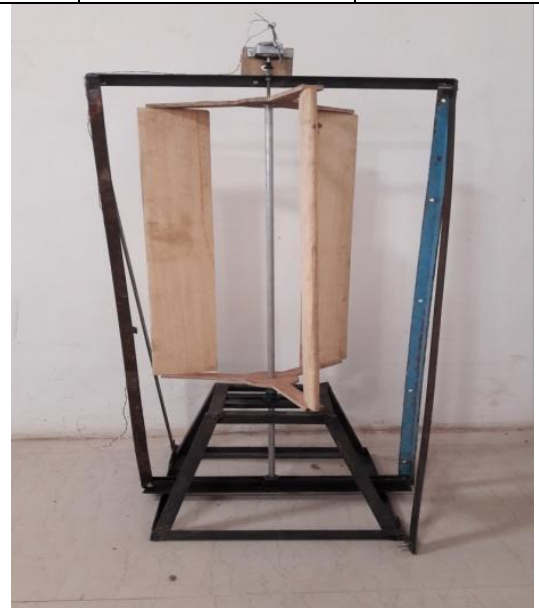

Fig.3 Vertical Axis Wind Turbine 


\section{Result and Discussion}

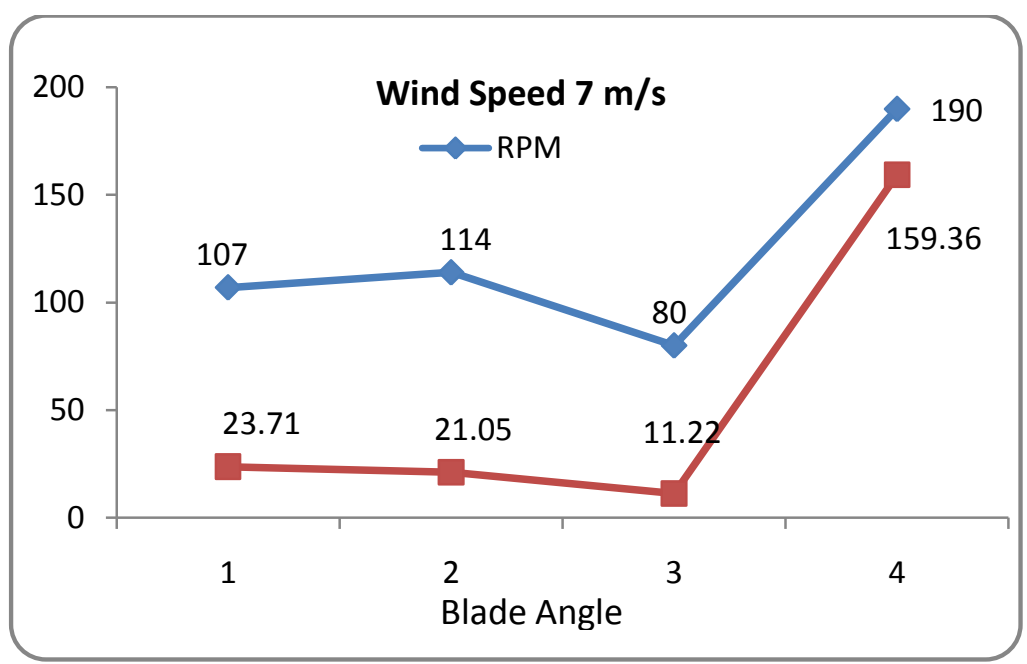

Fig 4 Graph at wind velocity $7 \mathrm{~m} / \mathrm{s}$

According to above graph it is observed at an angle of $90^{\circ}$ of blade angle it gives maximum power output.

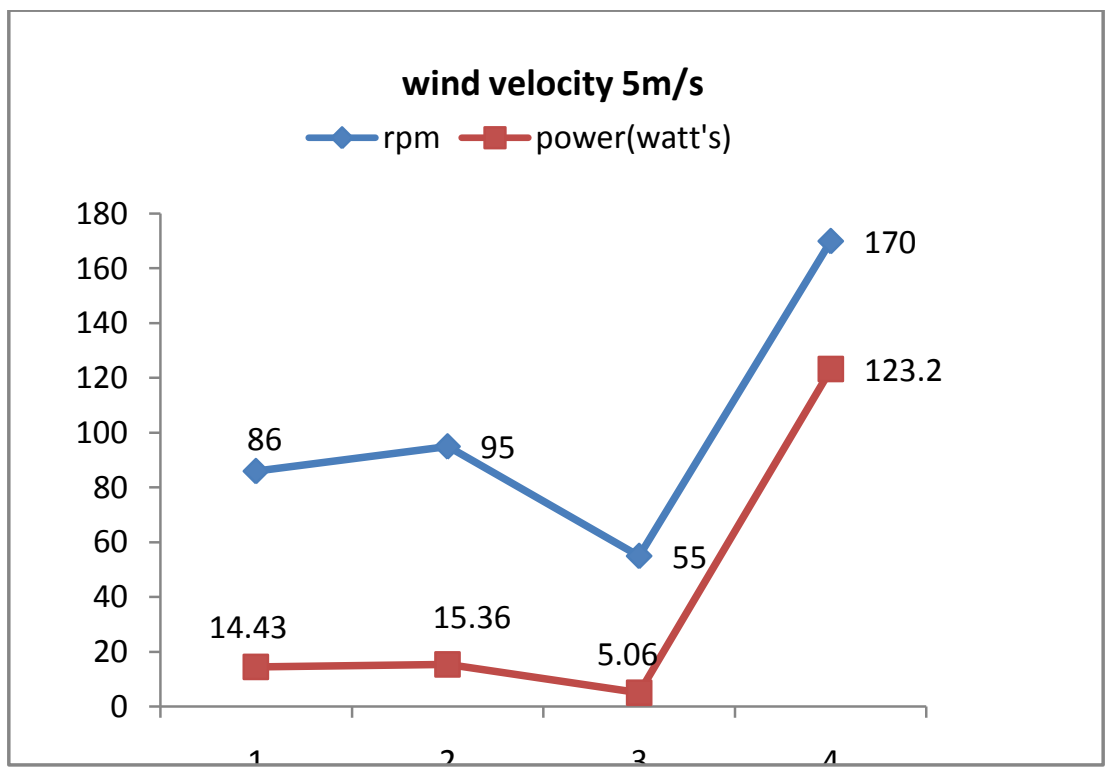

Fig 5 Graph at wind velocity $5 \mathrm{~m} / \mathrm{s}$

In above graph at point 3 means at an angle of $90^{\circ}$ it gives maximum power for velocity of $5 \mathrm{~m} / \mathrm{s}$ 


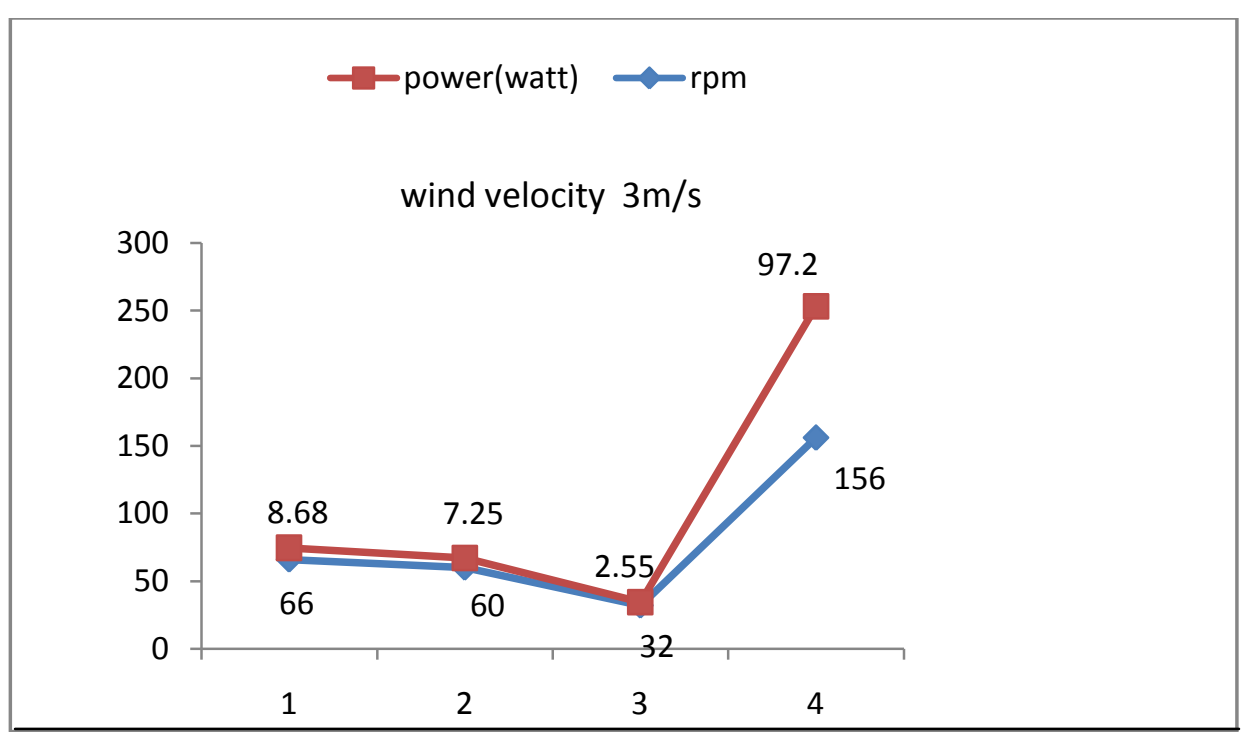

Fig.6 Graph at wind velocity $3 \mathrm{~m} / \mathrm{s}$

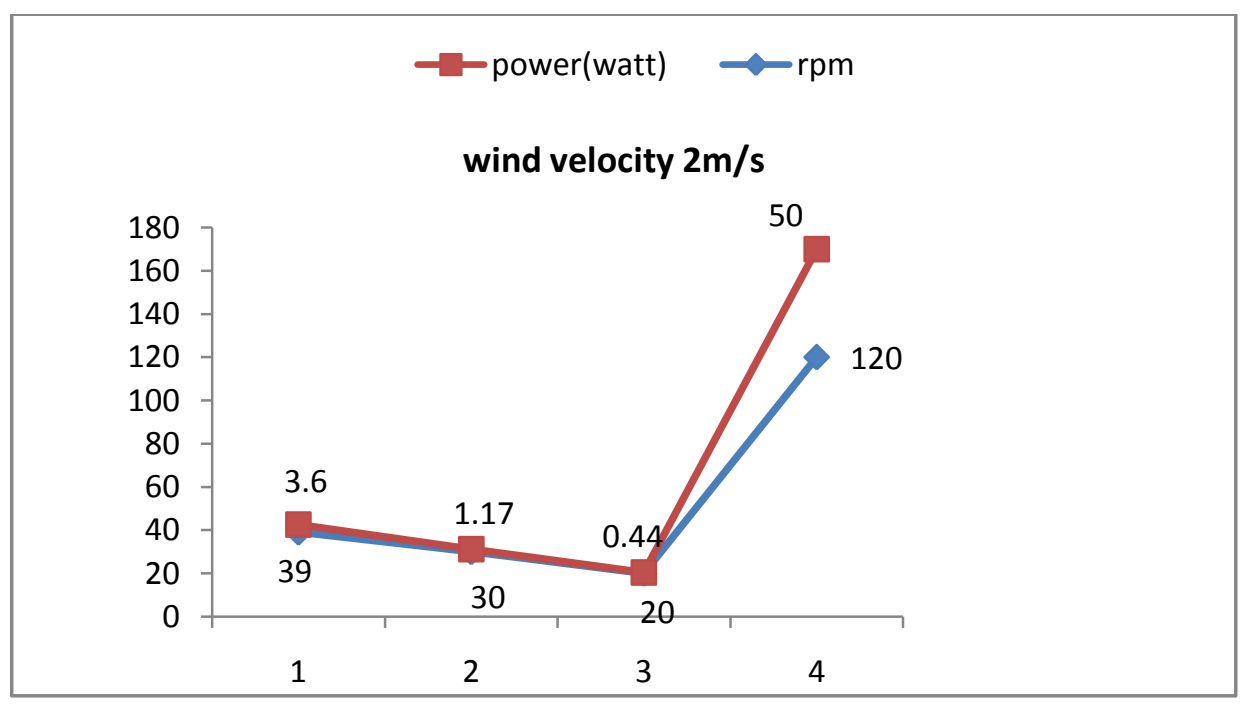

Fig.7 Graph at wind velocity $2 \mathrm{~m} / \mathrm{s}$

The graphs were plotted between Blade angles and Power Output for various air velocities. First of all, a common inference could be drawn after observing all the graphs that higher the wind velocity more is the power output.

Now, concentration was made on trends of low air velocities such as $2 \mathrm{~m} / \mathrm{s}, 3 \mathrm{~m} / \mathrm{s}$. It is observed that power output is goes on decreasing from angle 00 to 600 . This is because more amount of air energy goes in drag, and fewer amounts causes action of lift force over the blades.

But, it can be seen from plots that the power output sharply increases as the rigging angle approaches to 900 . Reason behind this is that maximum amount of wind energy is utilized in application of lift force, with a positive angle of attack. Drag is at its minimum. This is the most favorable condition for a lift type VAWT. Hence, the power output in this case is maximum for all the air velocities. 


\section{Conclusion}

This paper gives ideas to learn about the design and fabrication of complex Aerofoil blades. Vertical axis wind turbine represent a very promising future for wind power generation. A vertical wind turbine can give output more than conventional HAWT. The rotor that is designed to harness enough air to rotate the shaft at low and high wind speeds. The efficiency of turbine is increased by proper designing of the aerofoil shape blade, The major components are placed at the ground level which ensures the safety of turbine.

Thus, it can be concluded that Vertical axis wind turbine can produce power more with higher efficiency compared to traditional wind turbine. At a very low speed wind velocity Thus, this technology has the capacity to completely displace current technology in use for wind farms.

\section{Referance}

[1] http://www.turbinesinfo.com/darrieus-wind-turbines/

https://en.wikipedia.org/wiki/Darrieus_wind_turbine

[2] https://en.wikipedia.org/wiki/NACA_airfoil

[3] http://teachergeek.com/search?q=Types+of+wind+turbine

[4] http://centurionenergy.net/types-of-wind-turbines

[5]Khurmi.R.S, Jones.J.K, "A text book on Machine Design”, Eurasia publishing house, ISBN 81-2192524-X, 2003..

[6]S.Ramamruthan, R.Narayanan, "Strength of Materials 14 Edition", Dhanpat Rai publications, ISBN 81 87433-54-X, 2011, pp 406.

[7]Javier Castillo "SMALL-SCALE VERTICAL AXIS WIND TURBINE DESIGN", Bachelor's Thesis, Degree Program in Aeronautical Engineering, Tampere University of Applied Sciences, (Dec 2011

[8]Andrew Tendai zhuga, Benson Munyaradzi and Clement Shonhiwa, "Design of alternative energy system: A self-starting vertical axis wind turbine for stand alone application(charging batteries)" 